\title{
A Seedling Tray Conveying Device And Kinematic Analysis GUO Yi ${ }^{1, a^{*}}$, LIU Jiwei ${ }^{2, b}$ \\ Department of Horticulture Beijing Vocational College of Agriculture, Beijing China \\ aguoyibvca@163.com, b11900208@163.com
}

Keywords: seedling tray conveying device; slidercrank mechanism; kinematic analysis

\begin{abstract}
A seedling tray conveying device has been designed for conveying seedling trays for the production line during industrial cultivation of sprouts. The composition, working process and primary structural parameters of this device have been determined and virtually designed with SolidWorks. A kinematics model for the device has been established and analyzed with the Matlab-language-based program, to obtain the displacement, velocity, accelerating curve and variation range of the conveying rack. Kinematic analysis shows that change in kinematic parameters like displacement, velocity and acceleration of the conveying rack can realize conveying of the seedling tray. This device has been reasonably designed. The prototype test shows that the seedling tray conveying device can automatically convey the seedling trays from the transversal conveying chain to the longitudinal conveying chain in the sprout industrial cultivation production line. This device features simple structure, low cost, high efficiency, safe use and easy operation.
\end{abstract}

\section{Introduction}

With growth in the living standard, people are showing great favor for sprouts that feature rich nutrition, high quality and no pollution. Today, the sprout industry has developed into a rising vegetable industry with great potential. [1][2] Currently, sprouts mainly have 30 varieties, including the Chinese mahogany sprout, radish sprout and broadbean sprout.[3]

During operation of the sprout industrial cultivation production line, the seedling trays are delivered from the transversal conveying chain to the entrance of the longitudinal conveying chain and then to the longitudinal conveying chain. After that, they will be delivered by the longitudinal conveying chain when the longitudinal conveying chain is running. The working process is shown in Fig. 1. Currently the seedling tray conveying mode is divided into the semi-automatic one and the full-automatic one. Under the semi-automatic mode, seedling trays from the transversal conveying chain are pushed manually to the entrance of the longitudinal conveying chain. Under the full-automatic mode, the seedling trays from the transversal conveying chain are pushed to the entrance of the longitudinal conveying chain with the pneumatic reversing device. The semi-automatic mode requires manual operation and features heavy labor intensity and low efficiency. By contrast, the full-automatic mode adopts the pneumatic reversing device that features a complicated structure and high cost.



Fig. 1 Schematic Diagram for Conveying Process of the Seedling Tray 1-transversal conveying chain 2-seedling tray 3-transversal conveying direction 4-longitudinal conveying direction 5-longitudinal conveying chain 
In the design, the main structure is the slidercrank mechanism, which can be found in many studies. Zhou Li has made motion simulation for slidercrank mechanism by using Matlab/Simulink and obtained the motion curves of the connecting rod and the slider [4]. Liu Yongping and et al. made analysis of the movement characteristics of elliptical gear with slidercrank mechanism [5]. Su Quanwei and et al. conducted kinematics modeling and simulation of the slidercrank mechanism based on Simulink [6]. Liu Yong and et al. made kinematics and dynamics analysis of offset slidercrank mechanism based on Simulink [7]. Tian Xiaohong performed dynamics study on the slidercrank mechanism in smoke pusher hand based on ADAMS [8]. Wu Hao made motion analysis of four hinge slidercrank mechanism based on ProE [9]. Zhao Yugang performed motion simulation analysis for the slidercrank mechanism with the motion simulation module of the UG software [10]. He Yibin and et al. performed motion simulation of the slidercrank based on ADAMS [11]. Zhang Si and et al. made kinematic analysis of the slidercrank mechanism with the Pro/E software [12].

The seedling tray conveying device can automatically convey the seedling trays from the transversal conveying chain to the longitudinal conveying chain in the sprout industrial cultivation production line. This device features simple structure, low cost, high efficiency, safe use and easy operation.

\section{Design of the Seedling Tray Conveying Device}

Composition and Working Process. The seedling tray conveying device is composed of the rack, protective covering, conveying mechanism, step motor and controller. The conveying mechanism is composed of the crank, connecting rod, linear bearing, conveying rack (including sliding track, pusher plate and cambered plate). The seedling tray conveying device adopts the stepping conveying working principle [13]. When working, the step motor runs discontinuously (interval of 5 s for each cycle). The step motor drives the crank to rotate to work on the connecting rod, which will drive the conveying rack to make reciprocating motion along the linear bearing. When the transversal conveying chain delivers the seedling tray to the conveying device, the conveying rack pushes the seedling tray to the longitudinal conveying chain, when the conveying rack will go back to the original position and the step motor stop for $5 \mathrm{~s}$. When the transversal conveying chain delivers the seedling trays again to the conveying device, the step motor will be started again, when the conveying rack will push the seedling tray to the longitudinal conveying chain. The process is repeated to gradually push the seedling trays to the longitudinal conveying chain.

Design of Structural Parameters. The structural parameters of the device are determined according to the height, dimension and conveying distance of the seedling tray, as shown in Table 1.

Table 1 Structural Parameters of the Seedling Tray Conveying Device

\begin{tabular}{cc}
\hline Main Structure & Structural Parameters \\
\hline Rack & Length $\times$ Width $\times$ Height: $565 \mathrm{~mm} \times 430 \mathrm{~mm} \times 415 \mathrm{~mm}$ \\
Protective covering & Length $\times$ Width $\times$ Height: $570 \mathrm{~mm} \times 435 \mathrm{~mm} \times 115 \mathrm{~mm}$ \\
Crank & Length: $125 \mathrm{~mm}$ \\
Connecting rod & Length: $180 \mathrm{~mm}$ \\
Cambered plate & Length: $430 \mathrm{~mm}$ \\
Sliding track & Length:386mm \\
Pusher plate & Length: $430 \mathrm{~mm}$ \\
\hline
\end{tabular}

Design of the Seedling Tray Conveying Device. According to composition and structural parameters of the seedling tray conveying device and using the SolidWorks software, the virtual design of each part was finished. Then virtual assembly was performed. After that, the part interference examination was carried out, to modify part structures according to problems of part interference and kinematic collision of the mechanism. Thus, the seedling tray conveying device was designed. Fig. 2 shows the composition of the seedling tray conveying device. 


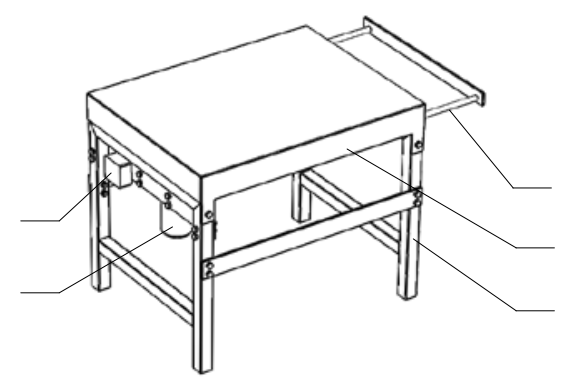

Fig. 2 Composition of the Seedling Tray Conveying Device

1-Rack;2-Protective covering ; 3-conveying mechanism; 4- controller;5- step motor

\section{Kinematic Analysis of the Seedling Tray Conveying Device}

Kinematic analysis is an important method to learn about the characteristics of a mechanism and is capable of indicating the motion conditions and evaluating the kinematic performance of the mechanism [14].

Establish the Mathematical Model for Kinematic Analysis. The seedling tray conveying device structure can be simplified into a slidercrank mechanism as shown in Fig. 3. This mechanism is a closed-loop plane link mechanism, which can be analyzed with the closed vector polygon method: first, establish a closed vector equation for the mechanism; second, obtain the velocity equation after getting the first derivative against time and obtain the acceleration equation after getting the second derivative against time [15].

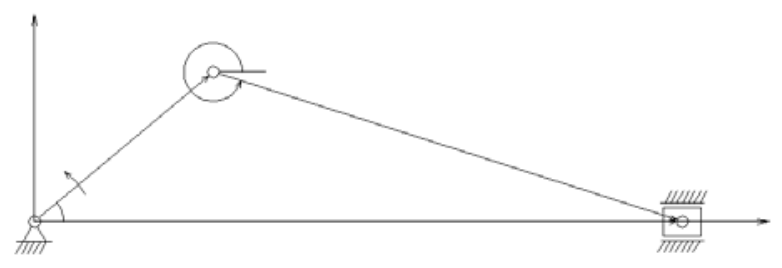

Fig. 3 Slidercrank Mechanism

To make kinematic analysis on the seedling tray conveying device, a system of rectangular coordinates as shown in Fig. 2 was built, taking the crank rotation centre as the origin, horizontal direction as X-axis and the vertical direction $\mathrm{y}$-axis. Each member is the vector of the member bar and is expressed with the complex representation in the exponential form.

According to Fig. 3, the closed vector equation formed by each member bar vector of the mechanism can be obtained from the closed polygon OABO:

$\overrightarrow{\mathrm{l}_{1}}+\overrightarrow{\mathrm{l}_{2}}=\overrightarrow{\mathrm{s}_{\mathrm{B}}}$

Where: $l_{1}$-length of crank $\mathrm{OA} / \mathrm{mm} ; \mathrm{l}_{2}$-length of connecting road $\mathrm{AB} / \mathrm{mm}$; $\mathrm{s}_{\mathrm{B}}$-displacement of conveying rack/ mm

The equation (1) can be expressed in the complex form as:

$\mathrm{l}_{1} \mathrm{e}^{\mathrm{i} \theta_{1}}+\mathrm{l}_{2} \mathrm{e}^{\mathrm{i} \theta_{2}}=\mathrm{s}_{\mathrm{B}}$

Where: $\theta_{1}$-rotation angle of crank $\mathrm{OA} /\left(^{\circ}\right) ; \theta_{2}$-angular displacement of connecting $\operatorname{rod} \mathrm{AB} /\left(^{\circ}\right)$

Separate the real part and the imaginary part of the equation (2) to obtain

$\mathrm{l}_{1} \cos \theta_{1}+\mathrm{l}_{2} \cos \theta_{2}=\mathrm{s}_{\mathrm{B}}$

$\left.\mathrm{l}_{1} \sin \theta_{1}+\mathrm{l}_{2} \sin \theta_{2}=0\right\}$

From equation (3) we can obtain the angular displacement $(\theta 2)$ of the connecting rod $\mathrm{AB}$

$\theta_{2}=\arcsin \left(\frac{-\mathrm{l}_{1} \sin \theta_{1}}{\mathrm{l}_{2}}\right)$

From equation (3) we can obtain the displacement of the conveying rack (sB)

$\mathrm{s}_{\mathrm{B}}=\mathrm{l}_{1} \cos \theta_{1}+\mathrm{l}_{2} \cos \theta_{2}$ 
Substitute (4) into (5) to get the displacement of the conveying rack (sB).

Get the first derivative of equation (2) against time (t) to obtain the velocity relational expression of the conveying rack as follows:

$\mathrm{il}_{1} \omega_{1} \mathrm{e}^{\mathrm{i} \theta_{1}}+\mathrm{il}_{2} \omega_{2} \mathrm{e}^{\mathrm{i} \theta_{2}}=\mathrm{v}_{\mathrm{B}}$

Where: $\omega_{1}$-angular velocity of crank $\mathrm{OA} / \mathrm{rad} \cdot \mathrm{s}^{-1} ; \omega_{2}$-angular velocity of connecting rod $\mathrm{AB} / \mathrm{rad} \cdot \mathrm{s}^{-1}$; $\mathrm{v}_{\mathrm{C}}$-linear velocity of conveying rack $/ \mathrm{mm} \cdot \mathrm{s}^{-1}$.

Separate the real part and the imaginary part of the equation (5) to obtain

$$
\left.\begin{array}{r}
\mathrm{l}_{1} \omega_{1} \cos \theta_{1}+\mathrm{l}_{2} \omega_{2} \cos \theta_{2}=0 \\
-\mathrm{l}_{1} \omega_{1} \sin \theta_{1}-\mathrm{l}_{2} \omega_{2} \sin \theta_{2}=\mathrm{v}_{\mathrm{B}}
\end{array}\right\}
$$

The equation (7) is expressed in the matrix form as:

$$
\left[\begin{array}{ll}
l_{2} \sin \theta_{2} & 1 \\
-l_{2} \cos \theta_{2} & 0
\end{array}\right]\left[\begin{array}{l}
\omega_{2} \\
v_{B}
\end{array}\right]=\omega_{1}\left[\begin{array}{c}
-l_{1} \sin \theta_{1} \\
l_{1} \cos \theta_{1}
\end{array}\right]
$$

Solve equation (8) to obtain the angular velocity of connecting rod $\mathrm{AB}\left(\omega_{2}\right)$ and linear velocity of the conveying rack $\left(\mathrm{v}_{\mathrm{B}}\right)$.

Get the second derivative of equation (2) against time (t) to get the conveying rack acceleration expression as:

$-\mathrm{l}_{1} \omega_{1}^{2} \mathrm{e}^{\mathrm{i} \theta_{1}}+\mathrm{il}_{2} \mathrm{a}_{2} \mathrm{e}^{\mathrm{i} \theta_{2}}-\mathrm{l}_{2} \omega_{2}^{2} \mathrm{e}^{\mathrm{i} \theta_{2}}=\mathrm{a}_{\mathrm{B}}$

Where: $\mathrm{a}_{2}$-angular acceleration of the connecting rod $\mathrm{AB} / \mathrm{rad} \cdot \mathrm{s}^{-2}$; $\mathrm{a}_{\mathrm{B}}$-acceleration of the conveying rack $/ \mathrm{mm} \cdot \mathrm{s}^{-2}$

Separate the real part and the imaginary part of the equation (9) to obtain

$$
\left.\begin{array}{l}
-\mathrm{l}_{1} \omega_{1}^{2} \cos \theta_{1}-\mathrm{l}_{2} \mathrm{a}_{2} \sin \theta_{2}-\mathrm{l}_{2} \omega_{2}^{2} \cos \theta_{2}=\mathrm{a}_{\mathrm{B}} \\
-\mathrm{l}_{1} \omega_{1} \sin \theta_{1}+\mathrm{l}_{2} \mathrm{a}_{2} \cos \theta_{2}-\mathrm{l}_{2} \omega_{2}^{2} \sin \theta_{2}=0
\end{array}\right\}
$$

The equation (10) is expressed in the matrix form as:

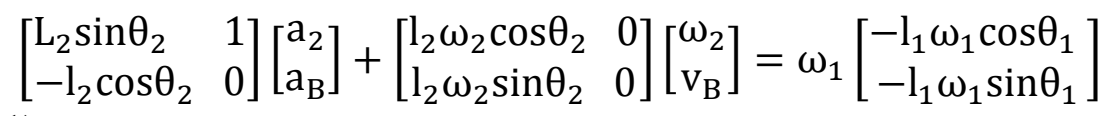

Solve the equation (11) to obtain the angular acceleration of the connecting rod $\left(\mathrm{a}_{2}\right)$ and acceleration of the conveying rack $\left(\mathrm{a}_{\mathrm{B}}\right)$.

Kinematic Analysis. According to the mathematical model for kinematic analysis and using the Matlab-language-based program, kinematic curves for displacement, velocity and acceleration of the conveying rack can be obtained and also the parameter variation scope and the crank angle corresponding to the limits. In this design, the angular velocity of crank $A B\left(\omega_{1}\right)$ is $3.14 \mathrm{rad} \cdot \mathrm{s}^{-1}$. Under counterclockwise rotation, the length of the crank $\left(l_{1}\right)$ is $125 \mathrm{~mm}$ and the length of connecting rod $180 \mathrm{~mm}$, with the kinematic analysis results shown in Fig. 4. The kinematic parameter variation scope was shown in Table 2. The foregoing analysis shows that change in kinematic parameters like displacement, velocity and acceleration of the conveying rack can push the seedling trays, indicating that this device has been reasonably designed.
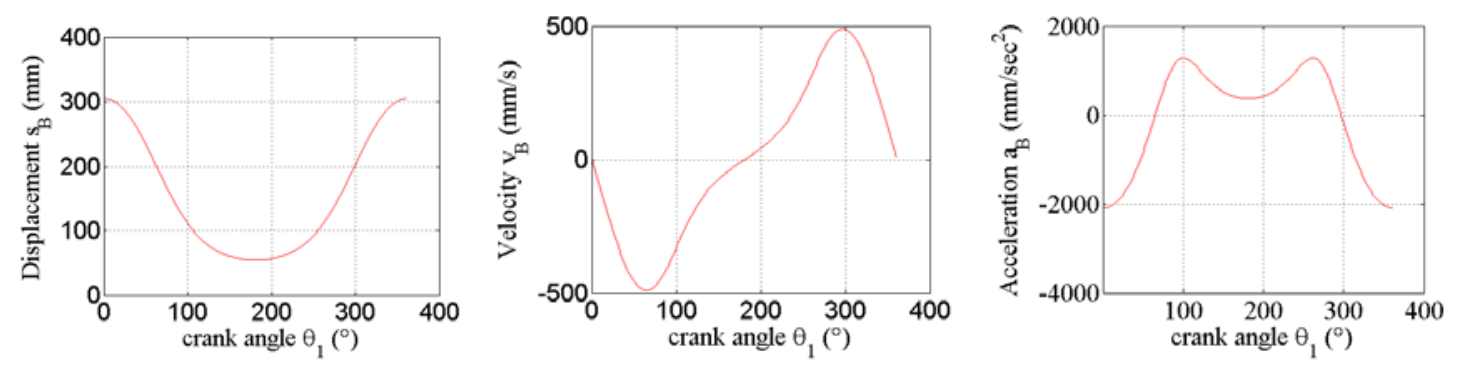

Fig. 4 Kinematic Analysis Results of the Conveying Rack 
Table 2 Kinematic Parameter Variation Scope of the Conveying Rack

\begin{tabular}{|c|c|c|c|}
\hline $\begin{array}{c}\text { Kinematics } \\
\text { Parameters }\end{array}$ & Varying Range & $\begin{array}{c}\text { Corresponding Crank } \\
\text { Rotation Angle of the } \\
\text { Minimum Value } \mathbf{(}^{\circ} \mathbf{)}\end{array}$ & $\begin{array}{c}\text { Corresponding Crank } \\
\text { Rotation Angle of the } \\
\text { Maximum Value } \mathbf{(}^{\circ}\end{array}$ \\
\hline Displacement & $55.0-305.0 \mathrm{~mm}$ & 180 & 0 \\
\hline Velocity & $-490.2-490.2 \mathrm{~mm} / \mathrm{s}$ & 64 & 296 \\
\hline Acceleration & $-2088.3-1285.8 \mathrm{~m} / \mathrm{s}^{2}$ & 0 & $99 \& 261$ \\
\hline
\end{tabular}

\section{Conclusion}

A seedling tray conveying device has been designed and its composition, working process and main structural parameters determined. A kinematics model for the device has been established and performed with the kinematic analysis, to obtain the displacement, velocity, accelerating curve and variation range of the conveying rack. Kinematic analysis shows that change in kinematic parameters like displacement, velocity and acceleration of the conveying rack can realize conveying of the seedling tray. This device has been reasonably designed.

Performance test has been made on the prototype made according to the designed seedling tray conveying device. The prototype test shows that the seedling tray conveying device can automatically convey the seedling trays from the transversal conveying chain to the longitudinal conveying chain in the sprout industrial cultivation production line. This device features simple structure, low cost, high efficiency, safe use and easy operation.

\section{References}

[1] WU Xian, WANG Xiuying, YANG Rui, WU Tong, Green Vegetable: Quality Projection Technologies for Sprout Sheds. Jilin Vegetable, 1( 2013)10.

[2] CUI Jin, ZHANG Xiaoyan, LU Yanwu, Application of LED Light Control Technology in Sprouts Cultivation. Science \& Technology Review, 10(2014)32-35.

[3] TAN Zizhen,LI Qingzhou, Disquisition on Application Feasibility of Seedling Vegetable Planting on High Seas Vessels. Journal of Anhui Agri. Sci, 2(2015)391-392.

[4] Zhou Li, Kinematics analysis and simulation of slider-crack mechanism based on MATLAB /Simulink. Mechanical Research \& Application, 04(2012)62-63.

[5] LIU Yongping, WANG Peng, XIAN Xilong, ZHANG Shi-yi, Analysis of the Movement Characteristics of Elliptical Gear with Crank-SliderMechanism. Machinery Design \& Manufacture, 12(2014)37-39+44.

[6] SU Quanwei, WANG Xiaokan, Kinematics modeling and simulation of the crank slider mechanism based on Simulink. Manufacturing Automation, 01(2014)72-73+94.

[7] LIU Yong, WANG Weihua, LI Zhigang, ZHANG Long, Kinematics and dynamics Analysisof offset Slidercrank Based on Simulink Mechanism. Technology and Engineering Science, 1(2014)186-191.

[8] TIAN Xiaohong, Dynamics Study on the Slider-crank Mechanism in Smoke Pusher Hand Based on ADAMS. Packaging Engineering, 3(2014)46-49.

[9] HAO Wu, Motion analysis of four hinge SliderCrank mechanism based on proe. Journal of Hubei Engineering University, 3(2014)121-123.

[10] ZHAO Yugang, WANG Zhanjun, CAI Tianci, LIU Xinyu, Motion simulation and finite element analysis for slider-crank mechanism of emulsion pump. Manufacturing Automation, 16(2014)74-76. 
[11] HE Yibin, HU Rongbo, LIU Hui, YANG Bingkuan, ZHANG Yu, Simulation of Slider Crank Based on ADAMS Motion. Journal of Hubei University of Technology, 8(2014)40-42.

[12] ZHANG Si,DONG Hai,XU Hongqin, Kinematic Analysis of Spatial Crank-Slider Mechanism. Mechanical \& Electrical Engineering Technology, 05(2014)44-46+92.

[13] ZHANG Zhanguo, SUN Lixia, Optimal Design of Stepping Workpiece Conveyor, Journal of Beihua University(Natural Science), 2(2015)272-275.

[14] WU Qingfeng, Analysis of Mechanism Kinematics Based on Matlab and Experimental Platform.Research and Exploration in Laboratory, 05(2014)140-143.

[15] YANG Yi, YANG Yongfa, SUN Youxiang, MATLAB-based Kinematic Analysis of the Planting Mechanism of Tobacco Seedling Transplanters. Forestry Machinery \& Woodworking Equipment,11(2011)40-42. 